\title{
Whose input counts? Evaluating the process and outcomes of public consultation through the BC Water Act Modernization
}

\section{ASHLEE JOLLYMORE}

\section{KIELY MCFARLANE}

Corresponding Author: kielymcfarlane@gmail.com

\section{LEILA M. HARRIS}

University of British Columbia, February 2017

Jollymore, A., McFarlane, K., and Harris, L.M. (2017) Whose input counts? Evaluating the process and outcomes of public consultation through the BC Water Act Modernization. Critical Policy Studies. doi:10.1080/19460171.2017.1282377

Citations of this work should use the final version as noted above 


\section{TABLE OF CONTENTS}

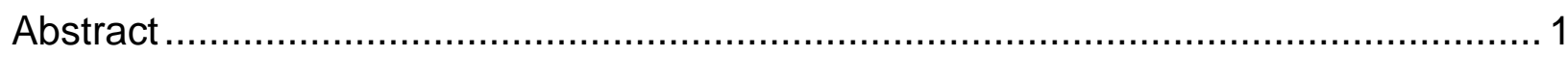

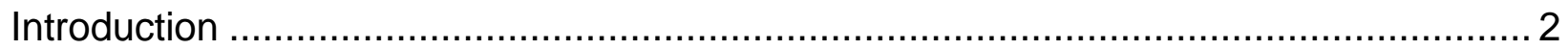

Evaluating participation: from process to outcomes .............................................. 4

Participation in environmental policy-making ........................................................ 4

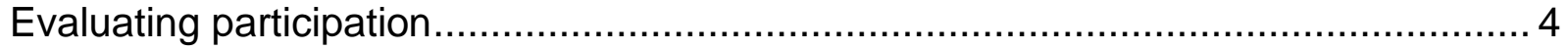

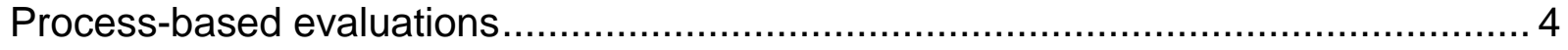

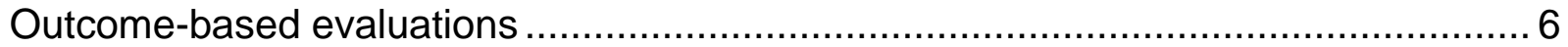

Case study background: the BC Water Sustainability Act (2014) ............................... 8

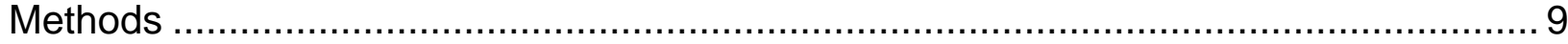

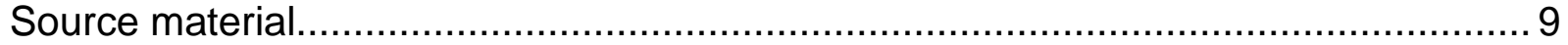

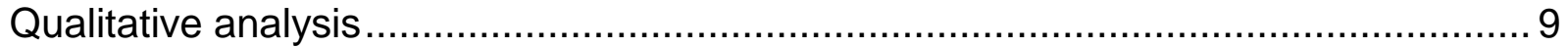

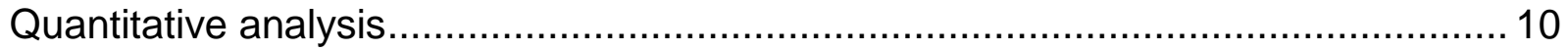

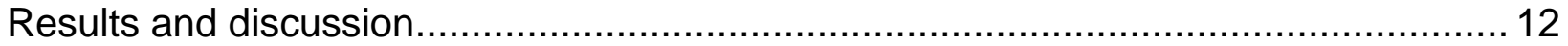

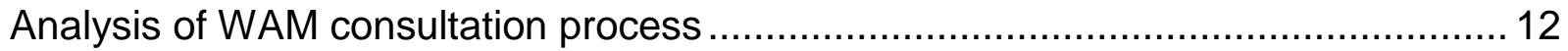

Submitter positions on WAM policy areas ……................................................ 14

Alignment of submitter positions with WSA policy outcomes ................................. 16

Assessing the impact of consultation............................................................... 19

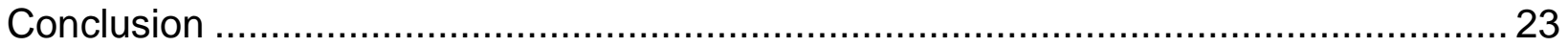

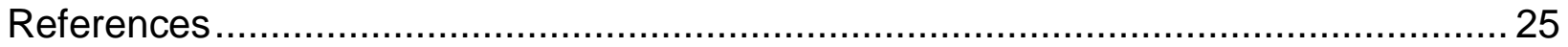




\section{ABSTRACT}

Public consultation has become an increasingly common form of democratic engagement. While critics have challenged the potential for public consultation to democratize policy-making due to existing power structures, few studies have undertaken a systematic evaluation of the policy outcomes of consultation. This study combines qualitative and quantitative techniques to systematically analyze participants' responses to policy proposals, and compare those responses with resulting policies. We utilized this approach to examine the large-scale public consultation process that informed the development of British Columbia's new Water Sustainability Act (2014). Our analysis revealed: 1) barriers to effectual engagement, particularly for First Nations; 2) statistical differences in policy preferences between industry and non-industry groups; and 3) patterns in how these preferences align with policy outcomes, suggesting uneven participant influence on policy-making. This study highlights the importance of analyzing consultation outcomes alongside process design, and the need to assess consultation's fairness and effectiveness by examining its outcomes for different participant groups.

Key words: consultation, participation, evaluation, policy making, democracy, water governance, Water Sustainability Act 


\section{INTRODUCTION}

Public consultation has become an increasingly important feature of policy-making (Shipley and Utz 2012), intended to promote broad citizen participation and enhance democratic engagement by enabling citizens to influence plans and policies that affect them (Patten 2001). While public consultation processes differ significantly in their format and outcomes, they are typically characterized by the solicitation of citizen feedback on a decision, plan, or policy proposal (Rowe and Frewer 2005), with the intention of informing government decisions or revisions to a proposal under consideration. Consultation processes are advocated as an inclusive, efficient means of gaining insight into public values and perceptions, which are expected to improve the outcomes, equity, and legitimacy of government decisions while retaining the central role of professional policy experts (Shipley and Utz 2012). However, public consultation has not always lived up to its democratic ideals; studies show that consultation processes often align poorly with decision-making processes, lack transparency, and have little influence on policy and planning (J. Carr 2012; Cheeseman and Smith 2001; Monno and Khakee 2012). Arnstein's (1969) seminal critique that consultation can be tokenistic, reproduce power hierarchies, and contribute to citizen disengagement continues to be echoed throughout the participation literature (e.g. Innes and Booher 2004; Kaehne and Taylor 2016; Woodford and Preston 2013).

The institutionalization of consultation techniques by democratic governments is therefore cause for concern, and demands critical analysis of how consultation reproduces or disrupts power hierarchies and contributes to social (in)justice for policy recipients. According to Fischer $(2016,97)$, critical policy analysis 'means not only to focus on problems, and the decisions designed to deal with them, but also to examine the normative assumptions upon which they are based.' In the context of public policy consultation, critical inquiry thus demands an engagement with the democratic assumptions underpinning consultation theory and practice (see Carvalho, PintoCoelho, and Seixas 2016; Patten 2001). Within this study, we employ the democratic principles of meaningful influence and equity as a normative framework with which to critically evaluate public policy consultation.

Although a range of evaluative criteria and frameworks have been developed to assess public participation processes (e.g. Beierle and Cayford 2002; Rowe and Frewer 2000), many of these lack an explicitly critical orientation. Recent reviews have highlighted that evaluations tend to emphasize process criteria and participant satisfaction, to the relative neglect of outcomes (Brown 2014; G. Carr, Blöschl, and Loucks 2012). In particular, systematic analyses of how consultation influences policy/planning outcomes are rare, making it difficult to examine consultation's role in perpetuating existing societal inequalities (Gilens and Page 2014). More explicitly critical evaluations that exist tend to focus on more direct and deliberative participatory processes (e.g. Carr 2012), rather than large-scale submission-based consultation processes that have become common among state and national governments (Kaehne and Taylor 2016). Little is consequently known about how large-scale processes contribute towards democratizing government decision-making. 
This study contributes to research on consultation evaluation through a detailed analysis of a recent large-scale, submission-based public consultation process. We develop a novel mixed methods approach to analyse both the consultation process and its policy outcomes with respect to principles of democracy. Our use of mixed methods echoes arguments by Harris et al. $(2016,14)$ that 'it is useful to pursue qualitative and quantitative work in tandem - allowing the quantitative work to reveal patterns that can then be explained and understood with more in-depth work.' In this study, qualitative analysis was used to explore themes in submitters' perceptions of policy proposals and the consultation process, while quantitative analysis revealed patterns in how submitter input aligned with policy outcomes. A mixed methods approach thus allows us to critically examine the consultation process with respect to meaningful influence and equity dimensions - indicating possible instances of uneven influence on policy-making - and to further interrogate the democratic assumptions embedded in consultation practices.

Our case-study, British Columbia's Water Act Modernization (WAM), provides an example of an intensive, multi-stage consultation process that received significant public attention and government investment. The provincial government held three rounds of public consultation over five years, resulting in over 4000 submissions. These submissions were used to refine policies that comprise BC's new Water Sustainability Act (WSA 2014). The consultation process has generally been considered successful, based on the large number of submissions generated and sustained engagement over multiple stages. As such, it is likely to influence future consultation exercises in BC and elsewhere.

We begin this article by reviewing existing literature on the evaluation of public participation processes, identifying key criteria and approaches to evaluate process design and outcomes. Following a brief background on the BC WAM, we describe the methods used to analyze submissions and policy outcomes. Subsequent sections summarize key strengths and limitations of the consultation process, variability in policy preferences across submitter groups, and differential alignment between policy preferences and outcomes. Finally, we discuss the politics of 'democratic' consultation, and challenges in providing accountability. 


\section{EVALUATING PARTICIPATION: FROM PROCESS TO OUTCOMES}

\section{Participation in environmental policy-making}

Public participation has been called a cornerstone of modern democracy, and is increasingly mandated in policy formation. This is especially evident within policy related to resource management, especially around issues of environment and sustainable development. The Aarhus convention (UNECE 1998) highlights interactions between the public and governmental authorities as key to justice considerations, focusing on the need for public access to information as well as broad engagement in decision-making. Participation is also one of the four key principles related to water governance highlighted in the Dublin Principles $(1992)$, while the OECD $(2001,11)$ states that:

'Engaging citizens in policy-making... contributes to building public trust in government, raising the quality of democracy and strengthening civic capacity'. Additional motivations for public participation include the inclusion of citizen knowledge and expertise, especially when institutional capacity is limited (Fischer 2000).

This focus on participatory engagement as key to good governance, and democracy broadly, has resulted in the institutionalization of consultation within public planning and policy-making (Shipley and Utz 2012), where submission-based consultation processes are a common means to solicit feedback, particularly in western democracies (Kaehne and Taylor 2016). The advent of the internet has transformed consultation, generating new mechanisms that enable broad, low-cost engagement through electronic platforms (Culver and Howe 2004). In Canada, participation in policy-making has a long history, traditionally operationalized through public hearings and citizen polls (Woodford and Preston 2013). In British Columbia, the requirement to consult on plans, regulations, and proposed activities is embedded within legislation (Halseth and Booth 2003). Specific requirements to consult and accommodate First Nations are also embedded in federal and provincial legislation (Government of Canada 2011).

\section{Evaluating participation}

The increasing prevalence of participatory policy-making has inspired a growing literature on process evaluation, including criteria and frameworks that evaluate participation's effectiveness and inclusivity, and empirical accounts of specific processes. While some of this work is specific to consultation, the majority relates to public participation generally. In this section we outline key trends in existing research on the evaluation of participation, focusing first on criteria to evaluate process design, and then on assessments of participation outcomes. A significant finding of this review is that while a range of approaches have been developed for process evaluation, there are few systematic analyses of participation outcomes. This study presents a novel approach that addresses this gap by linking process evaluation to policy outcomes.

\section{Process-based evaluations}

Multiple studies have identified a wide-ranging list of process-based criteria to evaluate fair and effective participatory processes. Over the last 20 years, these criteria have been consolidated in a number of frameworks for evaluating public participation, the most well-cited of which is Rowe and Frewer's (2000) framework of process and 
acceptance criteria (but see also Beierle and Cayford 2002; Blackstock, Kelly, and Horsey 2007; Brown 2014; Buchy and Hoverman 2000; G. Carr, Blöschl, and Loucks 2012). Common process criteria include early involvement, representativeness, inclusivity, adequate time and resources, access to information, clarity of objectives/agenda, and the ability of participants to provide input (Brown 2014). Criteriabased frameworks enable assessment of specific case-studies and comparison across processes (Rowe and Frewer 2004). However, Bickerstaff and Walker (2005) argue that generalized check-list approaches occlude power dynamics in participation. Scholars have also examined participatory processes using open-ended qualitative approaches, including participant observation, document analysis, and interviews (e.g. Bickerstaff and Walker 2005; J. Carr 2012; Carvalho, Pinto-Coelho, and Seixas 2016), highlighting barriers to meaningful engagement (particularly amongst marginalized populations, e.g. Morinville and Harris 2014), the politics of process design (e.g. Cheeseman and Smith 2001), and how process design and implementation affects participation (e.g. Halseth and Booth 2003).

Analyses identify the inclusivity and representativeness of participation as key considerations for process design. Studies examine both who participates (or does not) and how particular perspectives are represented (Catt and Murphy 2003). Paramount concerns include participation by marginalized groups, elitism, and the legitimacy of relying upon 'representative' individuals (Cornwall 2008; Nissen 2014; Parkins and Sinclair 2014). Several authors have in fact argued that participatory processes act to construct publics and interest groups, rather than simply representing pre-existing groups (Braun and Schultz 2010; Eden and Bear 2012).

A related set of concerns focus on access to participation, typically assessed in terms of process timing, resourcing, method, and location (Brown 2014). Studies have highlighted that the selection of participation techniques, as well as the timing and format of participation, can promote or inhibit participation by certain groups (Cornwall 2004; Parkins and Sinclair 2014). Submission-based consultation processes (including online consultation) can be prone to self-selection biases, promoting participation by those who are already politically engaged and have the time, resources, and expertise to participate (Kaehne and Taylor 2016). For example, Culver and Howe (2004) found that while online consultation improved participation rates, participants tended to be older, better educated, and more politically engaged than the general population. While limited access and familiarity with computers is noted to inhibit online participation, such forums can provide engagement opportunities for marginalized groups who would not normally participate in-person (e.g. survivors of domestic violence, Coleman 2004).

Finally, power dynamics are an important concern in evaluating participatory processes. Such dynamics are frequently observed in in-person processes (e.g. focus groups) due to pre-existing relationships, group identity politics, the presence of vested interests, and participants' differing abilities to make their concerns heard (Cornwall 2004).

Evaluative frameworks examine whether process design creates a safe environment for participants to voice opinions, accommodates their differing capacities, and provides facilitation for a fair and respectful process (Blackstock, Kelly, and Horsey 2007; Brown 2014). Studies emphasize the potential for 'elite capture' of participatory processes (Parkins and Sinclair 2014), and the silencing of particular perspectives due to identity 
politics (Koch 2013) and consensus-based processes (Bickerstaff and Walker 2005).

\section{Outcome-based evaluations}

Despite the recent advance of evaluative frameworks, very few studies assess consultation's effectiveness in terms of policy, planning, and resource management outcomes (see Brown 2014). Assessments of process effectiveness and participant satisfaction are frequently used as proxies for outcome evaluation, despite evidence that good processes do not necessarily lead to good outcomes (G. Carr, Blöschl, and Loucks 2012; Rowe and Frewer 2004). The lack of outcome assessment renders relationships between consultation and policy-making unclear, providing few measures to ensure decision-maker accountability (Bickerstaff and Walker 2005; Emery, Mulder, and Frewer 2015). Indeed, Bickerstaff and Walker $(2005,2132)$ conclude that 'one of the key questions for participatory democracy centres on what new deliberative processes are actually delivering in terms of policy outcomes.'

Evaluation frameworks typically assess acceptance of process outcomes, transparency, and accountability (Brown 2014; G. Carr, Blöschl, and Loucks 2012; Rowe and Frewer 2000). Acceptance criteria gauge whether participants and government officials accept and/or are satisfied with participation outcomes based on the perceived legitimacy of the process (Rowe and Frewer 2000), often based on surveys (e.g. Shipley et al. 2004). In contrast, transparency and accountability are typically assessed using simple indicators, including whether decision-making is structured and clearly articulated, consultation results are made available, and outcomes communicated to participants (Brown 2014; G. Carr, Blöschl, and Loucks 2012). While evaluation frameworks often contain criteria such as 'participant inputs have a genuine impact on policy' (J. Carr 2012), there are few measures to evaluate such impact (Emery, Mulder, and Frewer 2015; Rowe and Frewer 2004).

Additionally, some evaluation frameworks highlight the tangible and intangible outcomes of participation. Intangible outcome criteria include participant empowerment, social learning, willingness to participate in the future, increased trust of government, and improved understanding of government processes (Abelson and Gauvin 2006; Brown 2014). Tangible outcomes assess the 'products' that emerge directly from participation, including decisions, reports, plans, policies, and new institutions or processes (Shipley et al. 2004; Brown 2014; G. Carr, Blöschl, and Loucks 2012), although the nature and content of products is rarely analyzed. Intangible and tangible outcomes are typically evaluated using a combination of presence/absence criteria, document analysis, and participant surveys (Rowe and Frewer 2004).

Empirical analyses of consultation outcomes typically involve either observation or interview-based studies on how consultation impacts decisions (e.g. J. Carr 2012; Cheeseman and Smith 2001; Monno and Khakee 2012), or quantitative analyses of participant satisfaction with outcomes (e.g. Culver and Howe 2004). Very few studies have systematically analyzed the policy/planning impact of consultation - in other words, the relationship between consultation outputs (e.g. submissions) and policy outcomes. One notable exception is a 2014 study by Gilens and Page; their quantitative analysis of 1,779 public policy issues subject to public consultation in the US showed that 'when the preferences of economic elites and... organized interest groups are 
controlled for, the preferences of the average American appear to have only a minuscule, near-zero, statistically non-significant impact upon public policy' (575). Their results support other case-study analyses' findings of (economic) elite influence on public policy-making (J. Carr 2012; Kaehne and Taylor 2016; Parkins and Sinclair 2014). Studies also highlight government officials' role in limiting consultation's policy impact (Carvalho, Pinto-Coelho, and Seixas 2016; Cheeseman and Smith 2001). Here, we respond to the paucity of systematic analyses of consultation's policy outcomes by quantitatively analyzing the relationship between public submissions and resultant legislation across different submitter groups. 


\section{CASE STUDY: THE BC WATER SUSTAINABILITY ACT (2014)}

This study examines the public consultation process undertaken as part of the modernization of BC's Water Sustainability Act (WSA). This process was designed to update British Columbia's Water Act, which was established in 1909, and served as the primary legislation for managing the diversion and use of BC's water for over a century. Written for a settler state, it established a system of surface water property rights to enable the development of primary industries in the province. Subsequent amendments to the Act only marginally expanded its original focus, despite increasing evidence of water scarcity and water use conflicts in recent decades.

In 2008, the BC Ministry of Environment released 'Living Water Smart: BC's Water Plan', which included a commitment to modernize BC's water legislation by replacing the Water Act and attendant regulations with an act that would include protections for water resources and the environment. The Water Act Modernization (WAM) project commenced in 2010 with an intensive public consultation process (Figure 1).

Consultation took place over three stages and five years; each stage involved the release of a consultation document and solicitation of feedback on the policy information and options presented. The public were invited to submit comments via mail, fax, email, or the Living Water Smart blog. In addition, the government conducted 12 regional oneday workshops during the first phase of consultation, including three sessions specifically for First Nations.

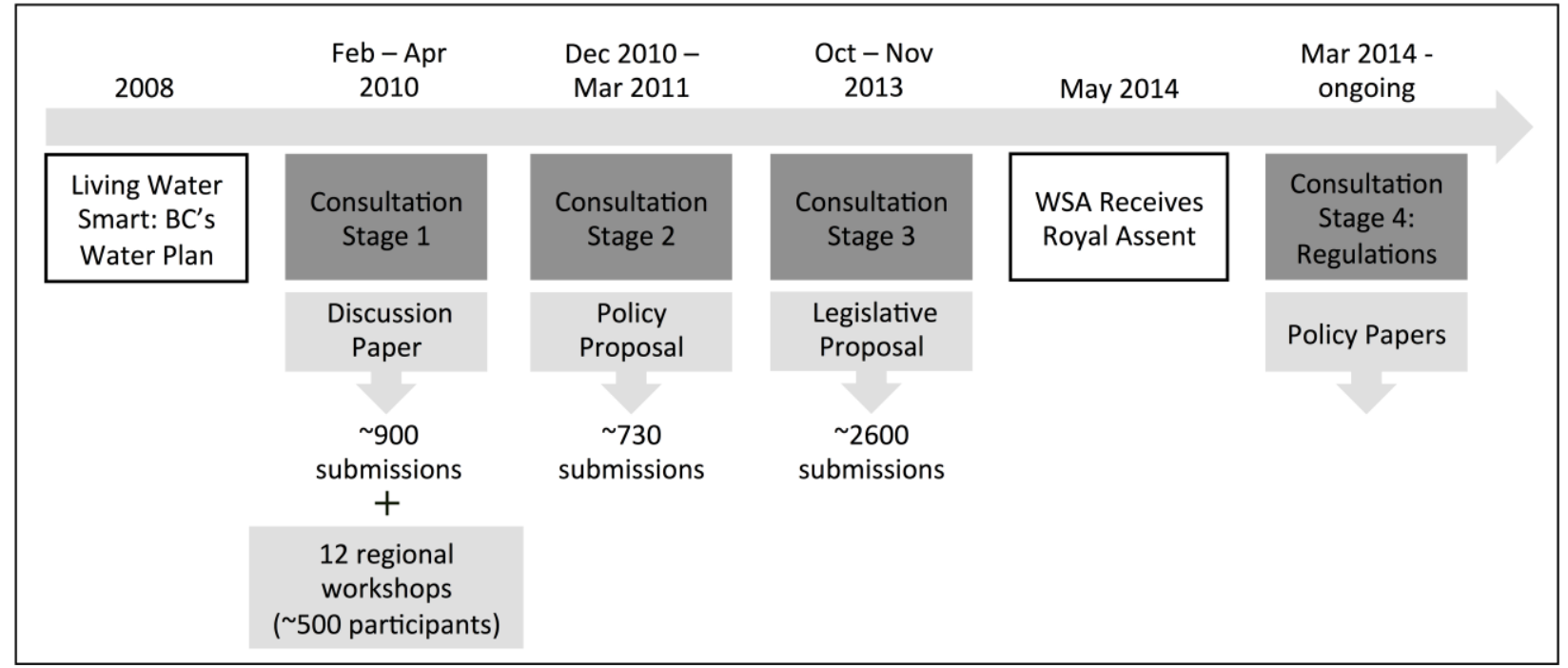

Figure 1 Water Act Modernization (WAM) process.

The WSA received royal assent in 2014, and came into force in February 2016 with the development of initial regulations. Over the coming years, further regulations that give effect to the Act will be developed in phases; the government has committed to continued public input on proposed regulations. Among the key policy revisions with the WSA are the introduction of groundwater licensing, the protection of environmental flows, and the ability to establish provincial water objectives, water sustainability plans for priority areas, and alternative governance arrangements. 


\section{METHODS}

\section{Source material}

Our analysis is based on submissions from the first three stages of consultation; the fourth stage had not been completed at the time of the analysis. Submissions were downloaded from the Ministry of Environment's website in May 2015. ${ }^{1}$ We retained the ministry's classification of submissions by submitter group and consultation stage to stratify submissions for our analysis.

All submissions were analyzed for 15 of the 16 submitter groups identified by the ministry. For the $16^{\text {th }}$ group, comprised of 'individual'" submitters, $10 \%$ (482) of submissions were randomly selected from each stage for analysis (using $R$ version 3.2.4; code at https://github.com/ashjolly/WSA Analysis) due to the large number of submissions from individuals, and resources available for analysis. In total, 867 submissions were analyzed across all 16 submitter groups (Figure 2) using a combination of qualitative and quantitative techniques.

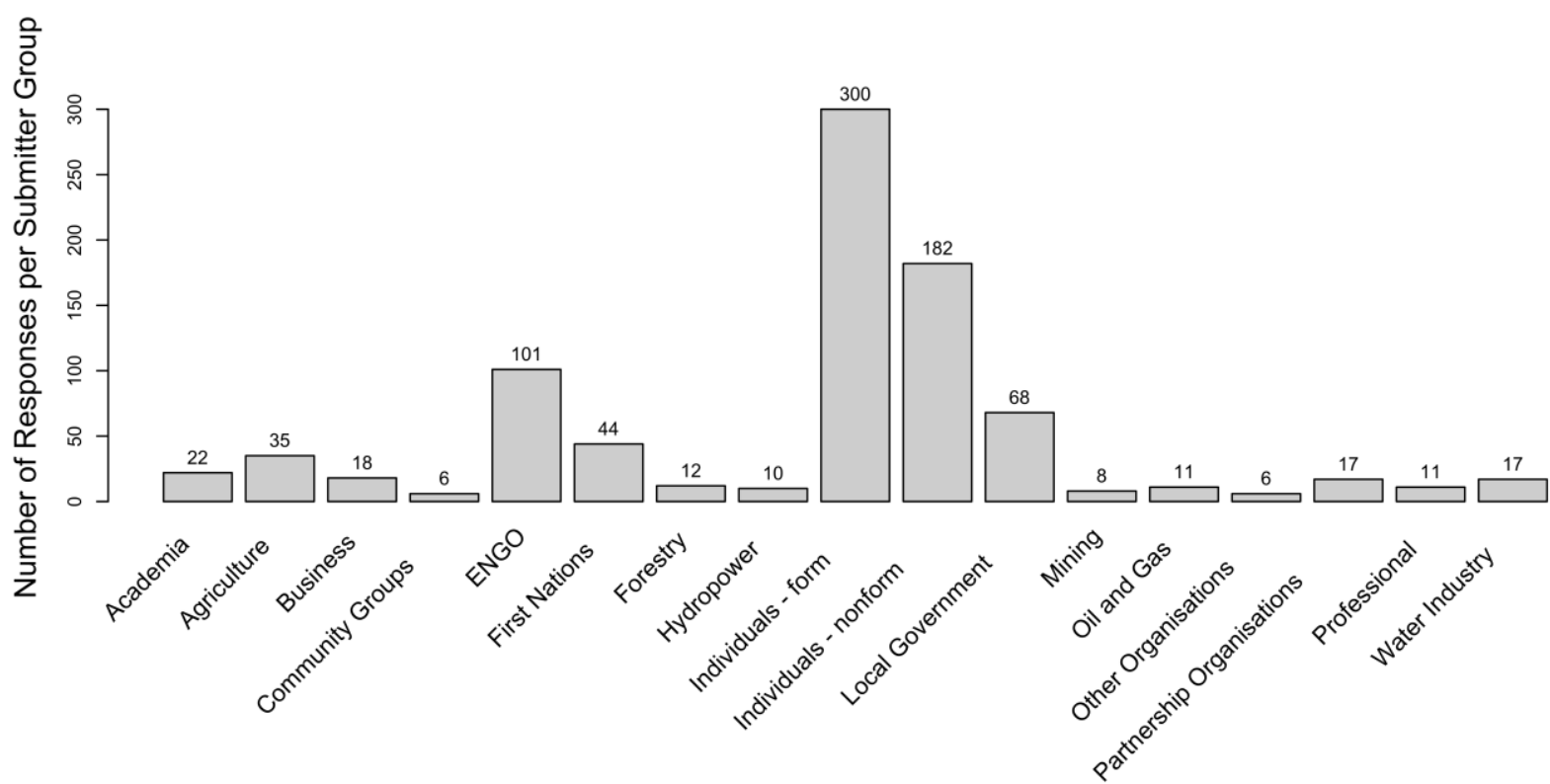

Figure 2 Number of submissions analyzed by submitter group (all consultation stages).

\section{Qualitative analysis}

Submissions were coded in NVivo (version 10.2.1, QSR International) using an iterative coding procedure focused on understanding how participants responded to the policy options raised during consultation. All statements that participants made in direct response to the policy options proposed in consultation documents were coded. The resulting codes were used to construct a coding rubric that reflects the range of policy

\footnotetext{
${ }^{1}$ https://engage.gov.bc.ca/watersustainabilityact/whatweheard/

2 The 'individuals' submitter group includes form-based and freestyle (non-form) submissions from unaffiliated individuals
} 
areas (26 in total) contained within consultation documents (Figure 3). Within each policy area, responses were coded according to the level of legislative intervention advocated by participants; responses were categorized as advocating either 1) a more transformative approach to water governance with stronger regulation, 2) a moderate degree of regulation, or 3 ) less or weakened regulation for that policy area.

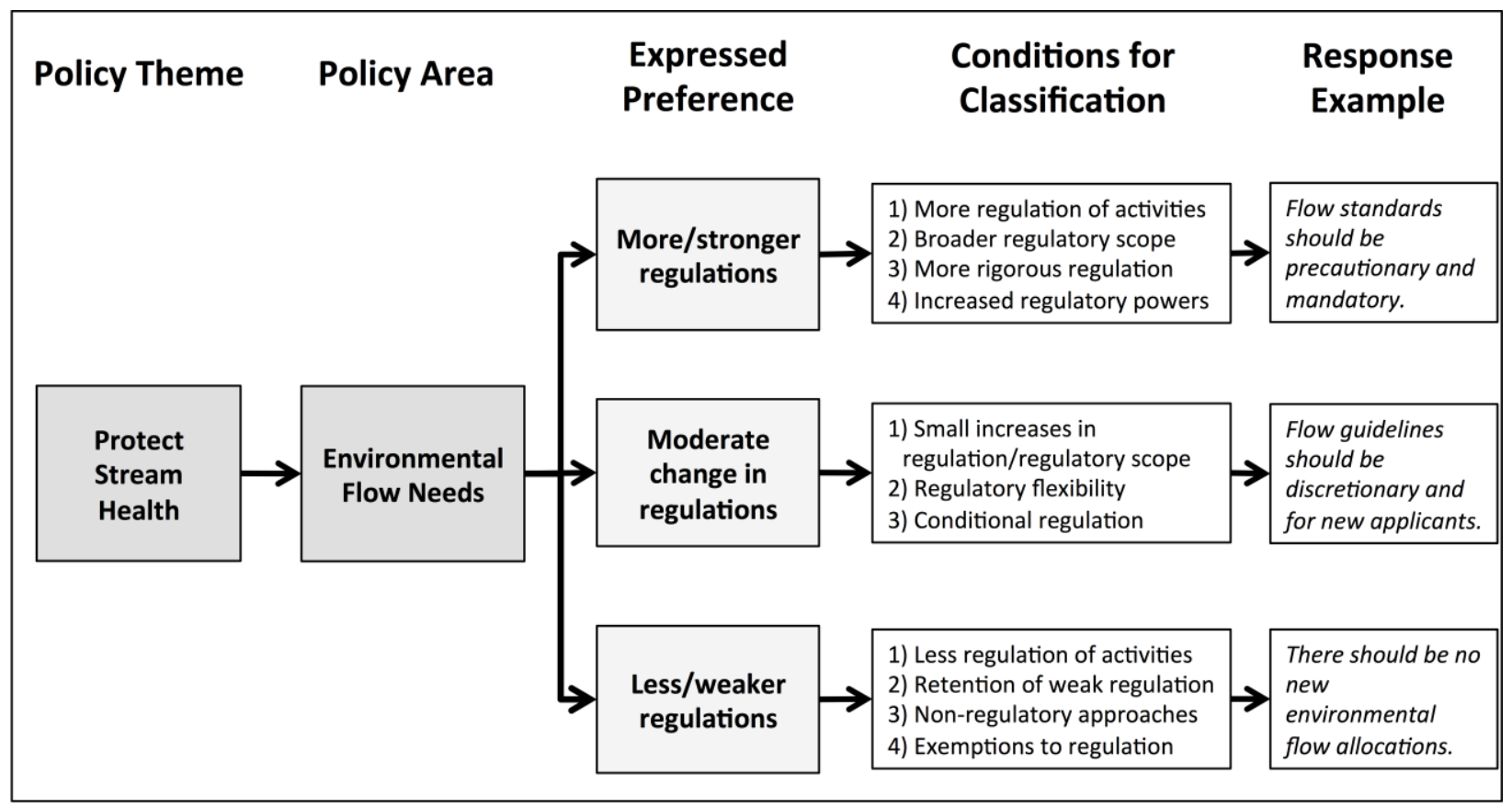

Figure 3 Method for coding submissions, based on policy areas contained in the WSA consultation documents. Submissions were analyzed on stated preferences for more, moderate, or weaker regulation (as per example).

In addition, submissions contained a large number of comments regarding the consultation process itself, revealing recurrent themes in submitter concerns and suggestions about the process. Such comments were coded as either positive or negative in tone, and according to themes in recommendations for the process.

Many submissions also contained policy ideas or concerns that were outside the scope of consultation, and are therefore not included in this analysis.

Given the number of submissions, coding was split between three individuals. All team members analyzed several submissions at the beginning of the process and compared results to ensure consistency. All results were reviewed at the end of the process by a single team member to ensure their proper identification and classification.

\section{Quantitative analysis}

To examine the relationship between submitter responses and final policy outcomes, a quantitative analysis of submitter responses to policy areas was then conducted using the coding rubric described previously. This analysis involved calculating two 'constructed metrics' (see Satterfield et al. 2013) - a 'response factor', and 'alignment factor' - using R (v. 3.3.1, R Core Team. 2016). 
Firstly, 'Response Factors' were calculated to identify how each submitter group responded to a specific policy area, in terms of their desire for more, less, or moderate levels of regulation:

Response Factor

$$
\begin{aligned}
& =\left(\frac{\text { Number of submitters desiring increase }}{\sum \text { responses in policy area for submitter group }}\right) * 101 \\
& +\left(\frac{\text { Number of submitters desiring moderate regulation }}{\sum \text { responses in policy area for submitter group }}\right) * 51 \\
& +\left(\frac{\text { Number of submitters desiring decrease }}{\sum \text { responses in policy area for submitter group }}\right) * 1
\end{aligned}
$$

The 'Response Factor' is the average number of submitters in a group that advocated a particular level of regulation, multiplied by a weighting factor, and summed across all regulation levels for a particular policy area. Weighting factors were chosen to ensure clear separation between groups advocating for more versus less regulation.

Secondly, 'Alignment Factors' were calculated to compare the level of regulation desired by submitters within specific policy areas (i.e. submitter group response factors) to the outcomes present within the WSA:

$$
\text { Alignment Factor = Response Factor }- \text { WSA Factor (2) }
$$

The 'WSA Factor' in this equation was calculated by coding the finalized WSA according to our rubric (Figure 3), identifying whether it represented strong, moderate, or weak regulation for the 26 policy areas in our analysis.

The 'Alignment Factor' measures the distance from the level of governance desired by a submitter group to the contents of the WSA. Thus, if the WSA contains the same level of regulation desired by a submitter group, the Alignment Factor will be close to 0; if the submitter group desired more regulation than contained in the WSA, the alignment factor will be closer to 100, and if submitters desired less regulation than the WSA, the alignment factor will be closer to -100 . 


\section{RESULTS AND DISCUSSION}

\section{Analysis of WAM consultation process}

Our analysis revealed that 182 submissions (21\% of all submissions) included some form of comment on the consultation process, of which $70 \%$ were negative in tone (cf. $6 \%$ positive), while $62 \%$ provided a recommendation on the process. The four most common recommendations were to provide more opportunities for input, to undertake meaningful consultation with First Nations, to extend the comment period, and to provide more information on proposed policies. Here we highlight these recommendations, together with our own observations, to explore some of the concerns related to the design of democratic consultation processes.

The most common recommendation among submitters was to provide more opportunities for public input. During the first stage of consultation, a discussion paper was released that invited the public to indicate their level of support for the proposed principles, objectives, and potential solutions outlined in the document. The discussion paper was necessarily very high level, and the government did not indicate that they were considering further consultation. Submitters consequently argued that if this government is serious about democracy, there should be a broader public input process instead of an insufficient 10 day review process' (Individual, Stage 1). The government responded to the public's requests for further input by providing two additional stages of consultation, each with an increasingly detailed policy proposal. This extension speaks to a high level of government investment in public participation, and the influence of initial consultation on overall process design, resulting in a multi-stage process where participants were involved from goal evaluation to policy analysis (as advocated by Patten 2001).

Submitters criticized the government for their lack of meaningful engagement with BC First Nations. For example, the Union of BC Indian Chiefs (Stage 1) stated that:

$U B C I C$ is deeply concerned that the submission process outlined in the Discussion Paper is highly problematic; it was designed without Indigenous involvement and treats Indigenous people as 'stakeholders' in the water policy process... There is no recognition of Indigenous jurisdiction or constitutionallyenshrined and judicially-recognized Aboriginal Title and Rights.

Such critiques were re-stated throughout consultation. Indeed, First Nations' submissions had the highest rate of negative comments on the WAM consultation process; $65.9 \%$ of all First Nations' submissions were negative in tone, compared to $14.7 \%$ of all submissions across all submitter groups. While we are unable to provide detail here, it is clear that consultation fell short of the government's legal responsibilities ${ }^{3}$, let alone broader ethnical guidelines on what might constitute

\footnotetext{
${ }^{3}$ A series of Supreme Court of Canada decisions in 2004-2005 established the government's constitutional duty to consult and accommodate First Nations on decisions that might impact their aboriginal or treaty rights (Government of Canada 2011). Further, the BC government entered into a 'New Relationship' with BC First Nations in 2005 to improve government-to-government relations. These two developments created legal and societal expectations that
} 
appropriate consultation.

Despite clear direction that the government has a specific responsibility to consult First Nations, the WAM consultation process was broadly framed in terms of public interest, and First Nations' input was incorporated as one among 16 'stakeholder' groups (rather than on a government-to-government basis). The creation of three (out of nine) workshops - the only attempt to specifically engage First Nations - was denounced as 'woefully inadequate' (First Nations Leadership Council, Stage 2). Indeed, of 198 First Nations in the province, only 18 made formal submissions to the process. ${ }^{4}$ This low response rate was likely due in part to the perception that public consultation was not an adequate replacement for the legal 'duty to consult' (Joe, Bakker, and Harris 2016; Simms 2014; Von der Porten and De Loë 2014). The Government's failure to fulfil their duty to consult, and dilution of First Nations' rights to those of 'stakeholders', has the potential to contribute to further mistrust, as well as disenfranchisement of First Nations (ibid).

Submitter comments identified the duration of consultation as another constraint, repeatedly requesting that the government extend the deadline for submissions. The third consultation stage was criticized as particularly insufficient; submitters were given just four weeks to respond to a 127-page legislative proposal. The consequences of short timeframes are unevenly distributed; whereas industry groups, academia, and government organizations have time and resources to dedicate to responding to consultation documents (Kaehne and Taylor 2016), individual citizens, NGOs, and other under-resourced groups are significantly disadvantaged by short timeframes (Cornwall 2008). Local governments and First Nations noted especially that there was insufficient time to consult with their communities and governing boards before formulating a response:

Whereas many organizations have a governance Board who's meeting schedule does not accommodate such a short timeline... the Board of the Cowichan Valley Regional District formally request the Ministry of Environment to extend the timeline for public submissions (CVRD, stage 3)

As such, consultation timing constrained the democratic potential of the process, and also undermined the democratic structure of existing institutions, limiting their ability to submit a representative, well-informed response.

The final concern raised by submitters was the limited policy information provided, with insufficient detail on proposed policies:

$(W)$ hen it comes to legislation, the devil is in the details. Unfortunately, we will not know those details until the act is presented to the Legislative Assembly... For many of us the answer to these questions will affect the way we do our jobs and how we provide water to our residents (Water Supply Association of BC, Stage 3)

the BC government would consult First Nations on the WAM, as it would affect aboriginal water use rights and watershed health within their territories.

${ }^{4}$ Another 16 First Nations organizations and individuals also made submissions. 
This stands in direct contrast to the government's stated 'interest in hearing about any possible unintended consequences that have not yet been considered' (Ministry of Environment 2013, iii). The lack of policy information limited both submitters' ability to provide an informed response, and the utility of responses for policy-making; confusion over policy implications contributed to puzzled and contradictory responses to certain policies. For example, the government's proposal to create a new 'oil and gas' water use purpose was met with strong opposition from both oil and gas submitters, and ENGOs, individuals, and First Nations. Oil and gas submitters worried that the new purpose 'would provide another opportunity for interest groups to delay development' (Devon Canada, Stage 3), while others assumed it would provide the oil and gas industry with 'special and legally-protected rights to use water' (Fraser Riverkeeper Society, Stage 3).

Similar confusion was evident in submitters' responses to 'transfer of rights' and 'permitted uses' policies. This confusion remained despite significant investment on the part of government to provide informational resources for submitters, including informational workshops, an online blog to respond to questions, and a background report on options presented in the discussion paper (stage 1). The contrast between submitters concerns over the lack of detail and the government's efforts to this end highlights information provision as a key challenge for public participation in policymaking.

\section{Submitter positions on WAM policy areas}

This section describes how submitters responded to the policy options and proposals outlined in WAM consultation documents. First, we examined the number of submissions contributed by each submitter group across all consultation stages (Figure 2), which revealed significant variability. Individuals were by far the largest single contributing group, with the majority of individual submissions originating from NGOprepared forms (300 of the 482 individual submissions coded). Following individuals, ENGO, Local Government, and First Nations submitter groups contributed the greatest number of submissions, while many industry submitter groups contributed few submissions - for example, hydropower, oil and gas, forestry, and mining each had less than 15 submissions.

We then examined how submitter groups responded to the WAM policy areas. We calculated a response factor (the average stated desire for strength of regulation) for each policy area a submitter group responded to. The response factor for each submitter group/policy area pair was compiled as a heat map (Figure 4). Response factors lie on a continuum from 1 to 101, where a response factor closer to 1 (grey) indicates a desire for less regulation, and that closer to 101 (dark blue) indicates a desire for stronger regulation. Additionally, submitter groups were clustered according to statistical similarity in response factors across all policy areas; these relationships are illustrated by the dendrogram to the left of Figure 4 (policy areas were also clustered; dendrogram not shown). 


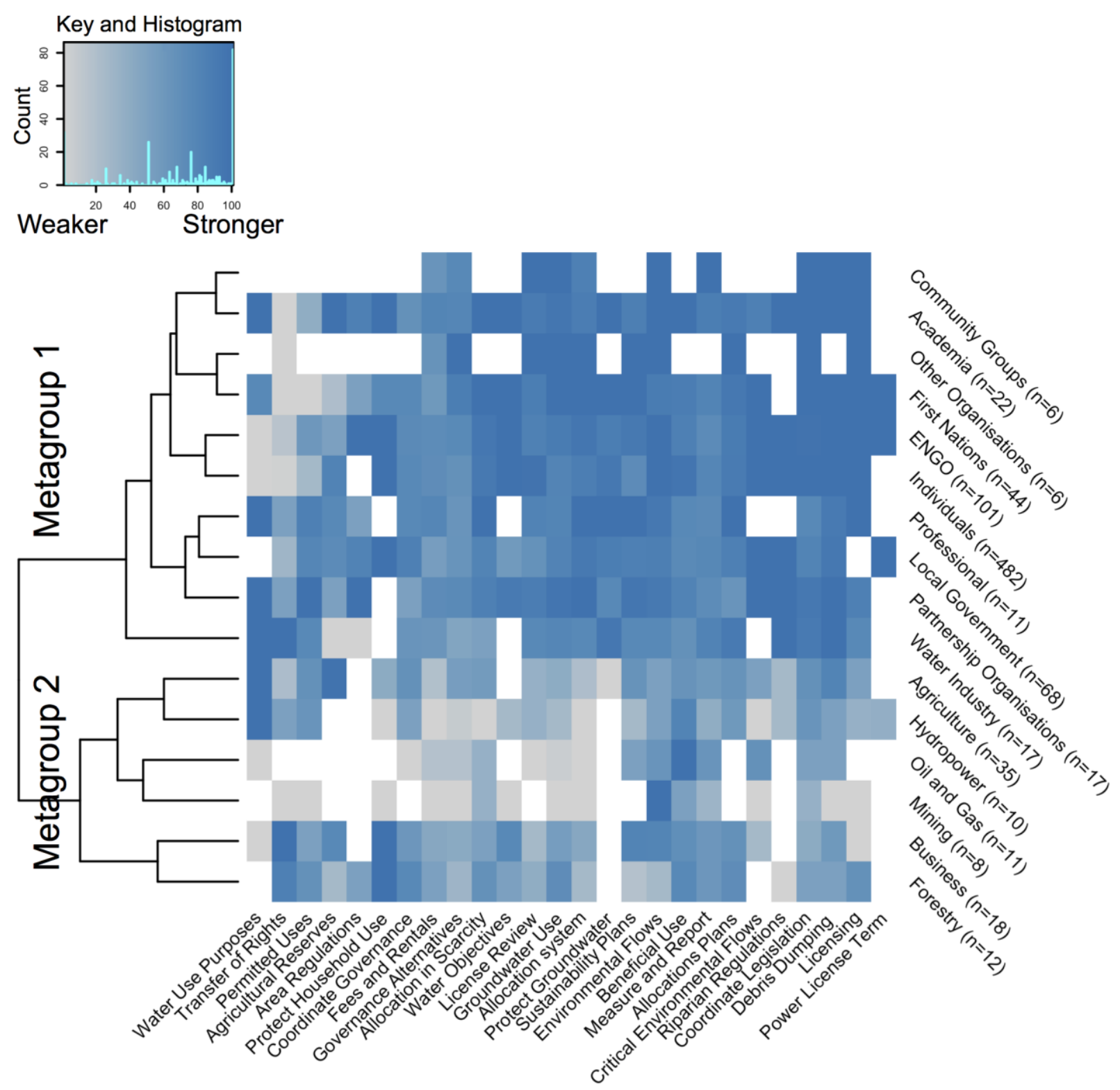

Figure 4 Response factors for each submitter group represented by heatmap pixels, clustered by similarities between submitters (rows) and policy area (columns).

The dendrogram identified two discrete submitter clusters - labelled Metagroups 1 and 2 (Figure 4). It is interesting to note that statistical clustering based on response similarities resulted in a strong aggregation of submitters best described as 'industrial'. ${ }^{5}$ This 'industry' group (Metagroup 2) - consisting of Agriculture, Hydropower, Oil and Gas, Mining, Business and Forestry submitters - tended to favour less regulation, as shown by the predominance of grey and light blue squares. For example, industry responses to policy areas related to allocation, licensing, governance, and groundwater

\footnotetext{
${ }^{5}$ Response and alignment factor clusters were determined through hierarchical cluster analysis using a complete linkage method without initial bias (number of clusters, composition, etc.).
} 
resulted in response factors close to or equal to 1, indicating a strong consensus within these groups towards less regulation overall.

Metagroup 2, comprised of 'non-industry' submitter groups (Community Groups, Academic, First Nations, ENGO, Individuals, Professionals, Local Government, Other Organizations, Partnership Organizations, and Water Industry6), is associated with higher response factors, signalling a desire for stronger overall regulation. This was especially true for policy areas enabling stronger environmental protections (e.g. Debris Dumping), improved governance (e.g. Coordinate Legislation), and stronger regulation of licensing (e.g. Licensing) - visible in the cluster of higher response factors at the top right of Figure 4. Submitters within this metagroup also exhibited a greater degree of internal similarity than submitters in Metagroup 2, as illustrated by the variability in colouration in Figure 4.

The internal similarity of response factors within Metagroups 1 and 2, along with the differences between them, suggests a similarity of interests and motivations within these groups. This is substantiated by qualitative analysis; within the industrydominated Metagroup 2, many submissions underlined the need for regulatory certainty and clarity regarding potential changes to water allocation systems. Further, submissions repeatedly emphasized the importance of protecting existing water rights to maintain industrial and economic activities:

(We are) able to optimize the water resources granted under its licences because of the certainty the current Water Act provides with respect to priority of allocation rights. A change ... could amount to an expropriation, with significant implications for energy planning, electricity rates, and provincial revenue. (BC Hydro, Stage 1)

In contrast, submissions in Metagroup 1 tended to emphasize other, non-economic considerations, including respecting First Nations' rights, current and intergenerational equity, over-allocation, and improving environmental protection. Thus, these groups appear to be motivated to participate by a desire to change the existing system, rather than to protect existing rights for economic benefits.

\section{Alignment of submitter positions with WSA policy outcomes}

The results of the alignment factor analysis for the 26 policy areas are illustrated in Figure 5. Each square represents the degree of alignment between a particular submitter group's response and the WSA policy outcome for a particular policy area. How well submissions aligned to WSA legislation is indicated along a colour continuum. Alignment factors indicated in blue indicate that the majority of submitters desired a greater degree of regulation than delivered within the WSA. Mustard yellow indicates that the majority of submissions within a particular submitter category called for less or weaker regulation than is contained within the WSA. Grey squares indicate where submitter preferences were reflected by the WSA, and white squares show where no

\footnotetext{
${ }^{6}$ The 'Water Industry' submitter group incorporates a wide range of submitters, including provincial water associations and consultancies, water utility companies and commercial suppliers, and water retailers (e.g. Nestle Waters Canada). Because the category encompasses a diverse range of views, it does not fit neatly into Metagroup 1 or 2 .
} 
submissions were made regarding that policy area (no data). Within Figure 5, both submitter groups and policy areas are clustered according to alignment factor similarities; the dendrogram to the left illustrates similarities between submitter groups based on their alignment factors. As observed in Figure 5, clustering of submitter groups according to alignment to the WSA results in the emergence of the same two broad submitter groups as observed when submitters are clustered according to their responses (Figure 4).
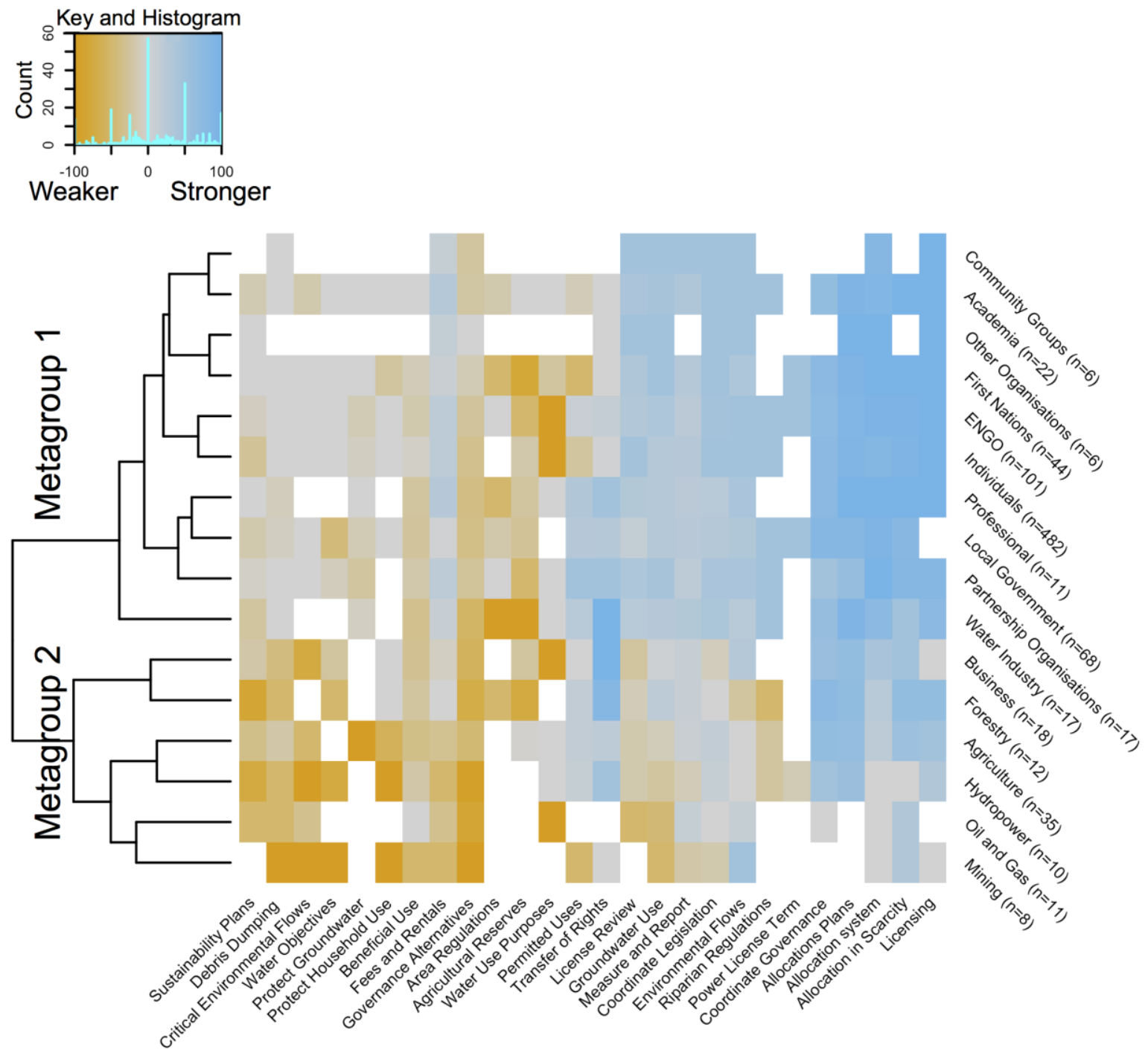

Figure 5 Alignment factors for each submitter group, describing the relationship between submitters' responses to consultation and WSA policy outcomes. Submitters (rows) and policy areas (columns) clustered by similarity.

The clustering of alignment values on the right of Figure 5 highlights a group of policy areas where the outcomes in the WSA aligned with the preferences of industry submitter groups (Metagroup 2). This cluster is comprised of policy areas related to water licencing and allocation, including 'allocation plans', 'allocation system', 'allocation in scarcity', and 'licensing'. Metagroup 2 advocated for weaker regulations that would 
maintain status quo approaches to licensing, ensuring the protection of existing water use rights. In contrast, Figure 5 reveals a near-uniform desire among non-industry submitter groups (Metagroup 1) - who represent the majority of submitters - for more regulation of these policy areas than is contained within the WSA. Non-industry submitters tended to advocate for strong regulation to ensure the sustainability of water resources, protection of priority uses (e.g. household use), and instatement of more equitable systems of allocation. Allocating and regulating water resources, in effect outlining who gets water and how, is a core component of water policy - indeed, it was the impetus for the initial Act over 100 years ago. However, as the strong division between non-industry and industry submissions indicates, these policy areas are also a key site of conflict in water legislation. The alignment between the licensing policies included in the WSA and Metagroup 2's policy preferences - rather than the majority of submitters - raises questions about how the consultation process fed into policy development, and thus the equity of policy outcomes.

To illustrate these possible divisions more clearly, we examined the response to the 'allocation system' policy area specifically across all submitter groups (Figure 6). This policy area captures submitter responses to the option to change the system of water allocation, raised during the first stage of consultation. Although the majority of submissions (82\%) advocated to replace the existing 'First in Time, First in Right' (FITFIR) system of allocation (where water rights are based on historical precedence of licences), the WSA retained this contentious allocation method. Figure 6 highlights that in contrast to submitters in industry groups, ${ }^{7}$ who mostly argued for the retention of FITFIR, submitters in non-industry groups tended to advocate for stronger regulation including allocation systems based on water use priorities or proportional water licences, along with increased community involvement in water licensing decisions. First Nations and partnership/environmental organizations were particularly strong advocates for a change in allocation system, as FITFIR has not recognized the historical precedence of First Nation water uses, nor protected water for households and the environment. This strong divergence between the degree of regulation called for and observed thus speaks to the unequal rights and privileges held by different submitter groups. One interpretation of the decision to retain FITFIR within the WSA is therefore that consultation privileges the voices of existing rights holders (status quo), resulting in the entrenchment of existing rights and power relations, and the valuation of economic elite interests beyond those of the majority.

\footnotetext{
${ }^{7}$ Water Industry is a clear exception to this trend. As stated previously, this category represents a range of stakeholders with divergent perspectives.
} 


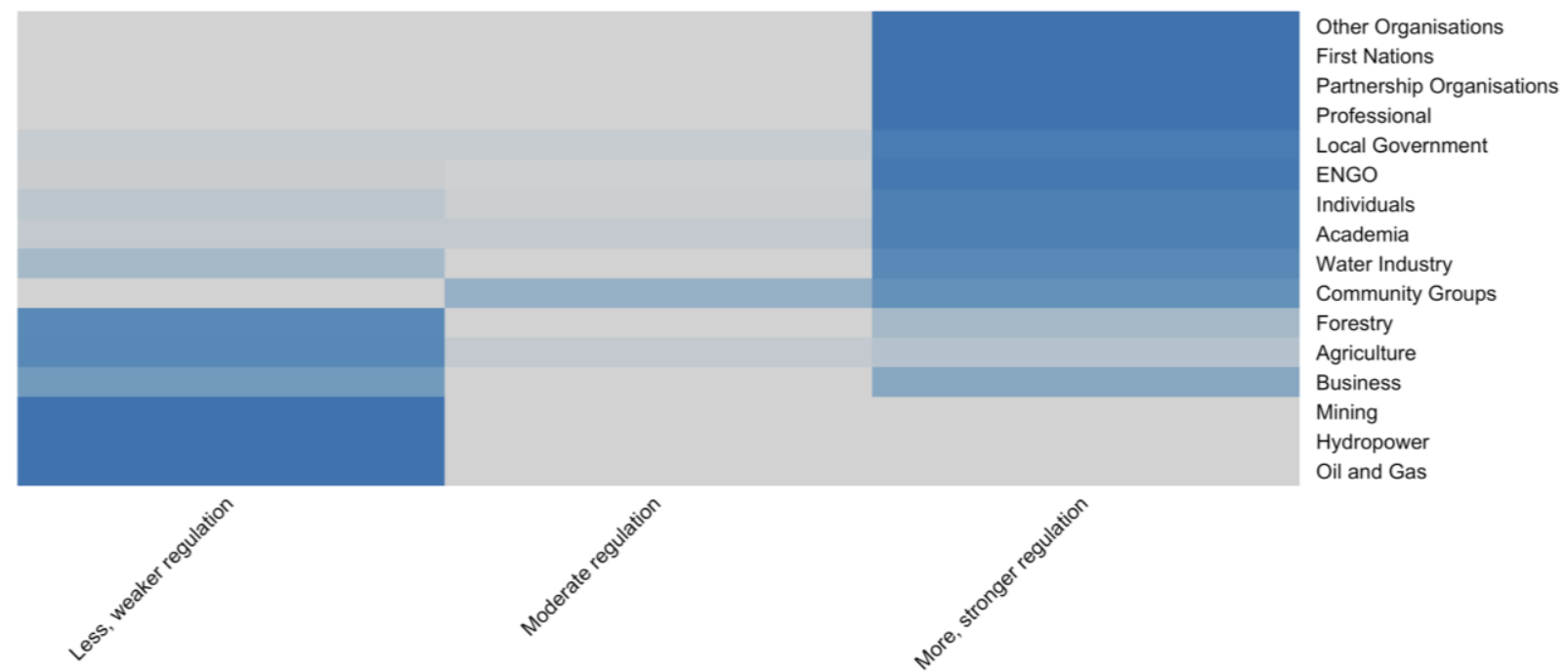

Figure 6 Percentage of submitter group advocating a particular level of regulation for the 'water allocation' policy area; dark blue $=100 \%$, grey $=0 \%$.

By way of contrast, close examination of the alignment factors on the left of Figure 5 reveals a cluster of policy areas that were subject to strong regulation in the WSA, as was advocated by non-industry (Metagroup 1) submitters, and resisted by many industry (Metagroup 2) submitters. It is notable that several of these policies are conditional, only applying to certain (priority) areas or times when the ministry deems it necessary. For example, new policies enabling the protection of critical environmental flows and household uses will only protect minimal flows/use volumes when a significant water shortage has been declared. Similarly, a ministerial order is required to develop water sustainability plans for designated priority areas (e.g. areas of sustained scarcity), while alternative governance arrangements for specific areas must be negotiated with the ministry. Other policy areas that received strong regulation under the WSA (i.e. prohibition on debris dumping, groundwater protection) represent preexisting regulations that have been strengthened with the WSA. In discussing these examples of 'strong' regulation in the WSA, we note that there is significant uncertainty regarding their final form, as this will be established through regulations currently under development.

In summary, our analysis of alignment factors illustrates that WSA policy outcomes align differently with perspectives of two primary groups: industry and non-industry submitters. While accounting for all elements that shaped the final contents of the WSA is beyond the scope of this paper, we do note that core elements of the WSA appear to align better with the level of regulation desired by a small subset of submitters (i.e. industry), particularly for key policy areas that define water rights and allocation. In contrast, policy outcomes that align with non-industry preferences tend to be conditional and discretionary. The following section reflects further on these trends, discussing implications of public consultation processes for democratic theory.

\section{Assessing the impact of consultation}

This article began by noting critiques of consultation's democratic potential, as well as 
the lack of systematic evaluation to assess consultation's democratic performance. In this study we sought to address this gap by comparing participants' inputs with the policy outcomes of a submission-based consultation process. This section invokes the democratic principles of influence and equity to address two questions from our analysis: 1) Does public consultation influence policy-making? 2) And if so, whose input counts in policy decisions?

In terms of consultation's influence on policy decisions, it is notable that the policy outcome aligned with the majority view for only half of the 26 policy areas addressed through the consultation. In this regard the policy impact of the consultation process is unclear. It appears that the majority public opinion shaped outcomes in only specific instances, while other considerations may have been paramount in other policy areas.

However, we note the large amount of government resources invested in consultation throughout the WAM, from the publication of submissions online, and the maintenance of an active blog, to the production of a summary of submissions highlighting controversial policy areas (Ministry of Environment 2010). Furthermore, policy documents published at each stage of the consultation process highlight that changes in policy did occur over the course of consultation. Most notably, the potential for transferring water rights and marketization approaches that appeared in initial policy proposals were removed in later iterations due to significant public opposition. As such, while our analysis does detail shortcomings, it would be difficult to discuss this process as merely tokenistic (cf. Arnstein 1969; Innes and Booher 2004).

Other evidence points against the idea that consultation served broader democratic aims of enabling public input into decision-making. The retention of FITFIR as a system of licencing is perhaps the most notable instance where a contentious policy was retained despite strong opposition across the majority of submitters and submitter groups. We note that other motivations for governments to invest in consultation beyond 'informing policy' may be a factor within this context, including interests in informing the public, procuring broader knowledge, addressing conflicts, and promoting wider citizen participation (see Fischer 2000). More critically, consultation in this instance may have served as a 'shadow referendum', enabling government to avoid policy change that might have spurred significant opposition from powerful (industry) groups (cf. J. Carr 2012).

From our results, unexplained differences in alignment between submitter input and policy outcomes speaks to opacity in the translation of public consultation into policy. Although motivations for undertaking public consultation were communicated at the outset, subsequent documents did not provide a clear account of how submissions were used to inform policy, or how other inputs shaped the ultimate composition of the Act. This lack of transparency regarding decision-making is a commonly noted issue in the literature (e.g. Halseth and Booth 2003). While governments may have good reasons for choosing particular policies over alternatives, the failure to clearly communicate policy rationales post-consultation reinforces perceptions that consultation is tokenistic, contributing to participation fatigue and citizen disengagement (Bickerstaff and Walker 2005; Murray, Fagan, and McCusker 2009). Systematic analyses of consultation outcomes, such as our own, may help to improve transparency and accountability by 
highlighting patterns of influence that warrant further explanation.

A key consideration we are only partially able to address is whether some submissions or submitters influenced policy outcomes more than others. Overall, our alignment factor analysis suggests inequality in submitter leverage on policy outcomes.

Specifically, the dominance of economic actors within submitter groups that aligned with contentious policy outcomes (especially key policies regarding water licensing, see Figures 5 and 6 ) lends weight to claims of elite access and influence on disputed policy developments (J. Carr 2012; Gilens and Page 2014). Indeed, the suspicion that the final WSA would favour elite interests was noted in several submissions:

As much as the stated goals of the WSA include environmental protection, the industry-specific approach outlined in the WSA eases the approval of industrial water uses with potentially harmful social and environmental consequences. $A$ dominant purpose of the WSA is to streamline water use and access by resource industries, such as mining and oil and gas. (Union of BC Indian Chiefs, Stage 3)

As such, our analysis provides further evidence that economic elites can have greater influence on key policy development than the general public, even when an open participatory process is undertaken (Parkins and Sinclair 2014).

The indication of elite influence in our results raises yet other questions about how such influence occurs, especially when participatory processes are as heavily resourced and carefully undertaken as the WAM. Together with J. Carr (2012), we suggest that the socio-political context of consultation, its design, and strategies employed by interest groups may serve to reinforce elite influence. In particular, rights-based arguments made by industry submitters, which emphasized economic and legal rationales for protecting existing entitlements, served to embed existing power relations within consultation. Additionally, several submissions from prominent industry groups mentioned consultation beyond the process open to all citizens. For example, formal submissions from Nestle Waters Canada mention discussions with high-level members of the Ministry of Environment, suggesting that they were provided additional spaces to voice their opinions. These findings suggest that the type of submitter and arguments made are more influential in decision-making than the quantity of support for policy options. On this point, it is worth reiterating that submitter groups whose perspective aligned with controversial policy outcomes tended to have fewer submissions than those who argued for alternative policies (Figure 2). This could derive from perceptions among powerful stakeholders that their interests will be accounted for no matter their level of participation within consultation, echoing broad concerns about the dominance of organized interests within participatory democratic processes (Gilens and Page 2014; Kaehne and Taylor 2016).

Our quantitative analysis of whose input 'counts' in public policy-making also revealed the practice of classification as an important influence on how submitters' views are represented and accounted for through consultation. Consultation evaluations typically assess process representativeness according to socio-economic and interest group characteristics of participants, compared with the general population (Rowe and Frewer 2000; Shipley and Utz 2012). However, our results highlight that representation is also a product of how participant views are made visible through the construction of submitter 
categories. As described by the Ministry of Environment $(2010,13)$ submissions were classified into categories based on 'submitters self-identifying as a representative of a particular group or organization'; submitters who did not self-identify were classified as 'individuals.' The Ministry then used these categories to quantitatively assess submitter responses to the objectives and policy options proposed. While there is nothing inherently wrong with this approach, the classification and analysis of submissions by submitter categories is inherently political, and should include an understanding of how this affects representation of minority versus majority interests.

By retaining the Ministry's classifications in our analysis, we were not only able to highlight the limited alignment between submitter input and policy outcomes, but also reveal concerns about the WAM classification and counting process. First, categories created by ministry officials to capture the diversity of submitters were somewhat arbitrary, and at times grouped submitters who would not necessarily have identified with specific categories. For example, a citizen who used his employer's address as a contact address was classified as a 'business' submission. In such cases, it was not clear whether the submitter intended to represent an organization, or had the authority to do so. Second, the arbitrary creation of categories obscured the diversity of views involved by reducing them to a series of discrete perspectives. For example, the category 'water industry' represents a wide range of submitters, from provincial water associations (who favoured strong regulation to promote sustainable water use), to water retailers (who supported the retention of existing regulations). By combining such opposing views under one category, neither perspective is clearly visible, which contributed to the weak relationship of 'water industry' to both Metagroups (as is evident in Figures 4-6). Third, we noted significant variability in the number of submissions per category, from six submissions from 'community groups', to 300 'individual form submissions' (see Figure 2). This variability in submissions is hidden when submitter positions are compared across categories (such as in Figures 4 and 5). Thus, classification according to submitter group has the effect of equalizing inputs across categories, effectively undermining the significance of a large number of responses from a particular group. Given the previously mentioned low number of submissions from many industry groups, the category-based analysis may have elevated their influence on decision-making. Fourth, a related concern voiced by ministry analysts is how to weigh submissions representing organizations (where one submission professes to speak for many people, e.g. an NGO or entire First Nation) against those representing individuals (Ministry of Environment 2010). All of these concerns speak to the very political nature of classification and counting, and the need for critical reflection on the effects of representational choices, including those that affected our own study design and results. This research therefore raises larger questions about the forms of democracy enacted through practices of consultation, and how they can entrench existing forms of political and material inequality. 


\section{CONCLUSION}

As public consultation is increasingly ubiquitous and mandated, and given criticisms regarding the outcomes and transparency of consultation (Arnstein 1969; Innes and Booher 2004), it is imperative to enrich frameworks to evaluate the equity and influence of consultation in policy-making. This study utilized a mixed methods approach to critically analyse both the process and outcomes of the multi-stage public consultation undertaken during British Columbia's WAM, according to principles of democracy. Our novel mixed methods approach enabled us to parse patterns of possible submitter influence by mapping submissions against policy outcomes, while also exploring how influence related to process design and the wider political-economic context. Our findings highlight the uncertain influence of consultation on policy-making, as well as the possibility of elite influence. We therefore argue that greater analysis of consultation inputs alongside policy outcomes is necessary to both examine possible inequities within consultation and hold governments accountable for policy decisions. Such evaluations are especially necessary as consultation becomes increasingly institutionalized as a means of participatory democracy (Shipley and Utz 2012; Kaehne and Taylor 2016).

Our quantitative analysis of submissions on the WAM revealed two distinct clusters in submitter groups' policy preferences, where industry submitters were more likely than non-industry submitters to state a desire for less/weaker regulation - views that tended to align with WSA outcomes on contentious policy issues such as water allocation. The emergence of these clusters and related patterns in policy alignment raise questions about how submitter voices are accounted within consultation, and whether such processes serve to counter or reinforce existing power dynamics. Qualitative analysis of submissions revealed that constraints in timing and resourcing of consultation, as well as limited policy information, served to constrain public input into the Act's development; this contrasted with access claimed by certain industry stakeholders in their submissions. In the Canadian context, the real or perceived entrenchment of certain interests over others is especially problematic given the government's (unfulfilled) constitutional responsibility to consult and accommodate First Nations, and the unresolved nature of their water rights.

In the spirit of reflexive critique, as outlined by Fischer (2016), our study draws attention to the normative assumptions and forms of democracy underlying consultation practice. In contrast to the simple public engagement narratives of government officials, this study illustrates the plural and contested nature of democracy in participatory policymaking. Our analysis of 'whose input counts?' raises the linked issue of 'whose input should count?', and what form of democracy this embodies. Public participation processes are frequently undergirded by an assumption of majoritarian democracy, where the majority or 'consensus' view is expected to inform policy (e.g. Gilens and Page 2014; Parkins and Sinclair 2014). However, work by Catt and Murphy (2003), Cornwall $(2004,2008)$, and Patten (2001) highlights that majoritarian processes can reinforce existing power dynamics and inequalities, and fail to address issues specific to minority and marginalized groups. Our study further demonstrates that interest group pluralism (as enacted through the creation of stakeholder categories) can enhance the 
influence of economic elites at the expense of more marginalized interests (see also Gilens and Page 2014). Particularly given the clear failures with respect to the duty to consult and accommodate First Nations, there are lingering questions about how to engage such groups in consultation processes, how to address specific rights and inequalities, and whether in some instances marginalized groups should have greater influence on decision-making.

Furthermore, our study highlighted analytical practices as a key site of democracy and accountability within consultation. Specifically, practices of 'counting' submitter input were complicated by variability in submitter types - including organizations, individuals, and form submitters. It is clear that different approaches to counting and/or weighting these submissions would deliver different outcomes for interest groups' influence on decision-making. The post-hoc classification of submitters into interest groups further obscured quantification of majority and minority views by implicitly equalizing the input of these groups. These findings highlight the representational effects of our analytical practices; in this case, 'whose input counts?' is tightly intertwined with how input is counted.

Our study indicates that evaluation of consultation must be informed by examination of the power relations implicit in participation. To the extent possible, it is important that studies of participatory democracy must be attentive to the different outcomes of policy decisions for different groups, with particularly focus on whether outcomes address or reinforce existing inequalities (Cornwall 2008). This study makes a modest contribution towards such analysis by providing a way to parse submitter input and analyze its alignment with policy outcomes, revealing patterns that can then be interrogated through further research. Such analyses of 'outcome equality' are likely to be most effective when undertaken in conjunction with critical interpretative analysis of the consultation process within its wider socio-political context. 


\section{REFERENCES}

Abelson, Julia, and Francois-Pierre Gauvin. 2006. Assessing the Impacts of Public Participation: Concepts, Evidence and Policy Implications. Research report P|06. Ottawa: Canadian Policy Research Networks.

Arnstein, Sherry R. 1969. "A Ladder of Citizen Participation." Journal of the American Institute of Planners 35 (4): 216-24. doi:10.1080/01944366908977225

Beierle, Thomas C., and Jerry Cayford. 2002. Democracy in Practice: Public Participation in Environmental Decisions. Washington, DC: Resources For The Future.

Bickerstaff, Karen, and Gordon Walker. 2005. "Shared Visions, Unholy Alliances: Power, Governance and Deliberative Processes in Local Transport Planning." Urban Studies 42 (12): 2123-44. doi:10.1080/00420980500332098

Blackstock, K. L., G. J. Kelly, and B. L. Horsey. 2007. "Developing and Applying a Framework to Evaluate Participatory Research for Sustainability." Ecological Economics 60 (4): 726-42. doi:10.1016/j.ecolecon.2006.05.014

Braun, Kathrin, and Susanne Schultz. 2010. "'“... a Certain Amount of Engineering Involved": Constructing the Public in Participatory Governance Arrangements." Public Understanding of Science 19 (4): 403-19. doi:10.1177/0963662509347814

Brown, Julia. 2014. "Evaluating Participatory Initiatives in South Africa: Not Just Processes but Outcomes Too." SAGE Open 4 (2): 1-16. doi:10.1177/2158244014531966

Buchy, M., and S. Hoverman. 2000. "Understanding Public Participation in Forest Planning: A Review." Forest Policy and Economics 1 (1): 15-25. doi:10.1016/S13899341(00)00006-X

Carr, G., G. Blöschl, and D. P. Loucks. 2012. "Evaluating Participation in Water Resource Management: A Review." Water Resources Research 48, no. W11401: 1-17. doi:10.1029/2011WR011662

Carr, John. 2012. "Public Input/Elite Privilege: The Use of Participatory Planning to Reinforce Urban Geographies of Power in Seattle." Urban Geography 33 (3): 420-41. doi:10.2747/0272-3638.33.3.420

Carvalho, Anabela, Zara Pinto-Coelho, and Eunice Seixas. 2016. "Listening to the Public - Enacting Power: Citizen Access, Standing and Influence in Public Participation Discourses." Journal of Environmental Policy \& Planning: 1-19. doi:10.1080/1523908X.2016.1149772

Catt, Helena, and Michael Murphy. 2003. "What Voice for the People? Categorising Methods of Public Consultation." Australian Journal of Political Science 38 (3): 407-21. doi:10.1080/1036114032000133967

Cheeseman, Graeme, and Hugh Smith. 2001. "Public Consultation or Political Choreography? The Howard Government's Quest for Community Views on Defence 
Policy." Australian Journal of International Affairs 55 (1): 83-100.

doi:10.1080/10357710120055094

Coleman, Stephen. 2004. "Connecting Parliament to the Public Via the Internet." Information, Communication \& Society 7 (1): 1-22. doi:10.1080/1369118042000208870

Cornwall, Andrea. 2004. "Introduction: New Democratic Spaces? The Politics and Dynamics of Institutionalised Participation." IDS Bulletin 35 (2): 1-10. doi:10.1111/j.1759-5436.2004.tb00115.x

Cornwall, Andrea. 2008. "Unpacking 'Participation': Models, Meanings and Practices." Community Development Journal 43 (3): 269-83. doi:10.1093/cdj/bsn010

Culver, Keith, and Paul Howe. 2004. "Calling All Citizens: The Challenges of Public Consultation." Canadian Public Administration 47 (1): 52-75. doi:10.1111/j.17547121.2004.tb01970.x

"The Dublin Statement on Water and Sustainable Development." 1992. Paper presented at the International Conference on Water and the Environment, Dublin, January 31.

Eden, Sally, and Christopher Bear. 2012. "The Good, the Bad, and the Hands-On: Constructs of Public Participation, Anglers, and Lay Management of Water Environments." Environment and Planning A 44 (5): 1200-18. doi:10.1068/a4495

Emery, Steven B., Henk A. J. Mulder, and Lynn J. Frewer. 2015. "Maximizing the Policy Impacts of Public Engagement: A European Study." Science, Technology \& Human Values 40 (3): 421-44. doi:10.1177/0162243914550319

Fischer, Frank. 2000. Citizens, Experts, and the Environment: The Politics of Local Knowledge. Durham: Duke University Press.

Fischer, Frank. 2016. "What is critical? Connecting the policy analysis to political critique." Critical Policy Studies 10 (1): 95-98. doi:10.1080/19460171.2015.1129350

Gilens, Martin, and Benjamin I. Page. 2014. "Testing Theories of American Politics: Elites, Interest Groups, and Average Citizens." Perspectives on Politics 12 (3): 564-81. doi:10.1017/S1537592714001595

Government of Canada. 2011. Aboriginal Consultation and Accommodation: Updated Guidelines for Federal Officials to Fulfill the Duty to Consult. Ottawa: Department of Aboriginal Affairs and Northern Development Canada.

Halseth, Greg, and Annie Booth. 2003. "'What Works Well; What Needs Improvement": Lessons in Public Consultation from British Columbia's Resource Planning Processes." Local Environment 8 (4): 437-55. doi:10.1080/13549830306669

Harris, Leila, Danika Kleiber, Jacqueline Goldin, Akosua Darkwah, and Cynthia Morinville. 2016. "Intersections of gender and water: comparative approaches to everyday gendered negotiations of water access in underserved areas of Accra, Ghana and Cape Town, South Africa." Journal of Gender Studies: 1-22.

doi:10.1080/09589236.2016.1150819 
Innes, Judith E., and David E. Booher. 2004. "Reframing Public Participation: Strategies for the 21st Century." Planning Theory \& Practice 5 (4): 419-36.

doi:10.1080/1464935042000293170

Joe, Nadia, Karen Bakker, and Leila M. Harris. 2016. Perspectives on the B.C. Water Sustainability Act: First Nations Respond to Water Governance Reform in British Columbia. Vancouver: Program on Water Governance.

Kaehne, Axel, and Helen Taylor. 2016. "Do Public Consultations Work? The Case of the Social Services and Well-Being (Wales) Bill." Public Policy and Administration 31 (1): 80-99. doi:10.1177/0952076715595676

Koch, Natalie. 2013. "Technologising the Opinion: Focus Groups, Performance and Free Speech." Area 45 (4): 411-18. doi:10.1111/area.12039

Ministry of Environment. 2008. Living Water Smart: British Columbia's Water Plan. Victoria, BC: Government of British Columbia.

Ministry of Environment. 2010. British Columbia's Water Act Modernization: Report on Engagement. Victoria, BC: Government of British Columbia.

Ministry of Environment. 2013. A Water Sustainability Act for B.C.: Legislative Proposal. Victoria, BC: Government of British Columbia.

Monno, Valeria, and Abdul Khakee. 2012. "Tokenism or Political Activism? Some Reflections on Participatory Planning." International Planning Studies 17 (1): 85-101. doi:10.1080/13563475.2011.638181

Morinville, Cynthia, and Leila M Harris. 2014. "Participation, Politics, and Panaceas: Exploring the Possibilities and Limits of Participatory Urban Water Governance in Accra, Ghana." Ecology and Society 19 (3), no. 36. doi:10.5751/ES-06623-190336

Murray, Michael, G. Honor Fagan, and Paul McCusker. 2009. "Measuring Horizontal Governance: A Review of Public Consultation by the Northern Ireland Government between 2000 and 2004." Policy \& Politics 37 (4): 553-71.

doi:10.1332/030557309X462556

Nissen, Sylvia. 2014. "Who's in and Who's Out? Inclusion and Exclusion in Canterbury's Freshwater Governance." New Zealand Geographer 70 (1): 33-46.

doi:10.1111/nzg.12038

OECD (Organization for Economic Co-operation and Development). 2001. Engaging Citizens in Policy-Making: Information, Consultation, and Public Participation. Public Management Policy Brief No. 10. Paris: OECD Publishing.

Parkins, John R., and A. John Sinclair. 2014. "Patterns of Elitism within Participatory Environmental Governance." Environment and Planning C: Government and Policy 32 (4): 746-61. doi:10.1068/c1293

Patten, Steve. 2001. "Democratizing the Institutions of Policy-Making: Democratic Consultation and Participatory Administration." Journal of Canadian Studies 35 (4): 221 39. 
R Core Team. 2016. R: A Language and Environment for Statistical Computing. R Foundation for Statistical Computing, Vienna, Austria.

Rowe, Gene, and Lynn J. Frewer. 2000. "Public Participation Methods: A Framework for Evaluation." Science, Technology \& Human Values 25 (1): 3-29.

doi:10.1177/016224390002500101

Rowe, Gene, and Lynn J. Frewer. 2004. "Evaluating Public-Participation Exercises: A Research Agenda." Science, Technology \& Human Values 29 (4): 512-56.

doi:10.1177/0162243903259197

Rowe, Gene, and Lynn J. Frewer. 2005. "A Typology of Public Engagement Mechanisms." Science, Technology \& Human Values 30 (2): 251-90.

doi:10.1177/0162243904271724

Satterfield, Terre, Robin Gregory, Sarah Klain, Mere Roberts, and Kai M. Chan. 2013. "Culture, Intangibles and Metrics in Environmental Management." Journal of Environmental Management 117: 103-14. doi:10.1016/j.jenvman.2012.11.033

Shipley, Robert, Robert Feick, Brent Hall, and Robert Earley. 2004. "Evaluating municipal visioning." Planning Practice \& Research 19 (2):195-210. doi:

10.1080/0269745042000284412

Shipley, Robert, and Stephen Utz. 2012. "Making It Count: A Review of the Value and Techniques for Public Consultation." Journal of Planning Literature 27 (1): 22-42. doi:10.1177/0885412211413133

Simms, Beatrice Rose. 2014. "'All of the Water That Is in Our Reserves and That Is in Our Territory Is Ours": Colonial and Indigenous Water Governance in Unceded Indigenous Territories in British Columbia." Master's thesis, University of British Columbia.

UNECE (United Nations Economic Commission for Europe). 1998. Convention on Access to Information, Public Participation in Decision-Making and Access to Justice in Environmental Matters, Signed 25 June 1998 at Aarhus, Denmark. Geneva: UNECE.

von der Porten, Suzanne, and Rob C. de Loë. 2014. "Water Policy Reform and Indigenous Governance." Water Policy 16 (2): 222-43. doi:10.2166/wp.2013.046

Water Sustainability Act. SBC 2014 c.5. British Columbia, Canada, May 292014.

Woodford, Michael R., and Susan Preston. 2013. "Strengthening Citizen Participation in Public Policy-Making: A Canadian Perspective." Parliamentary Affairs 66 (2): 345-63. doi:10.1093/pa/gsr065 